\title{
Associations between parental report of the home food environment and adolescent intakes of fruits, vegetables and dairy foods
}

\author{
Nicole I Hanson ${ }^{1, *}$, Dianne Neumark-Sztainer ${ }^{1}$, Marla E Eisenberg ${ }^{1}$, Mary Story ${ }^{1}$ and \\ Melanie Wall ${ }^{2}$ \\ 'Division of Epidemiology, School of Public Health, University of Minnesota, 1300 South 2nd Street, Suite 300, \\ Minneapolis, MN 55454, USA: ${ }^{2}$ Division of Biostatistics, School of Public Health, University of Minnesota, \\ Minneapolis, MN, USA
}

Submitted 26 February 2004: Accepted 13 July 2004

\begin{abstract}
Objective: This study examines parental report of household food availability, parent dietary intake and associations with adolescent intakes of fruits, vegetables and dairy foods.

Design: Cross-sectional study. Adolescents completed the Project EAT survey and the Youth Adolescent Food Frequency Questionnaire at school. Parents of adolescents were interviewed by telephone about the home food environment, eating habits and weight-related behaviours. General linear modelling was used to compare dietary intakes of adolescents across different levels of household food availability and parental intakes.

Subjects/setting: The study sample included 902 adolescents and their parent or guardian.

Results: Many parents were not consuming the minimum number of daily recommended fruit (44.5\%), vegetable $(69.9 \%)$ or dairy $(46.9 \%)$ servings. While most parents reported that fruits and vegetables were available at home (90.3\%) and vegetables were usually served at dinner (87.0\%), fewer parents reported milk was served at meals (66.6\%). Soft drinks were usually available at home (56.8\%). Among girls, household availability was positively associated with fruit and vegetable intake $\left(t_{\text {trend }}=2.70, P<0.01\right)$ and soft drink availability was inversely associated with dairy intake $\left(t_{\text {trend }}=2.08, P=0.04\right)$. Among boys, serving milk at meals was positively associated with dairy intake $\left(t_{\text {trend }}=3.65, P<0.01\right)$. Parental intakes were positively associated with dairy intake for boys $\left(t_{\text {trend }}=2.04, P=0.04\right)$, and with dairy $\left(t_{\text {trend }}=2.43, P=0.01\right)$, vegetable $\left(t_{\text {trend }}=3.72, P<0.01\right)$ and fruit $\left(t_{\text {trend }}=3.17\right.$, $P<0.01$ ) intakes for girls.

Conclusions/applications: Interventions designed to help adolescents improve consumption of fruits, vegetables and dairy foods may be enhanced by including a parental component aimed at increasing household availability and parents' intake of healthful food choices.
\end{abstract}

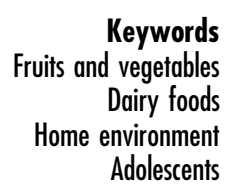

National nutrition data indicate that adolescents are consuming excessive amounts of high-fat, high-sodium foods and inadequate amounts of whole grains, fruits, vegetables and dairy foods ${ }^{1}$. These dietary patterns place adolescents at risk for obesity and may affect their risk for future chronic disease ${ }^{2-6}$. Family plays a major role in determining the dietary patterns of youth; studies of family resemblance in diet have demonstrated parent-offspring associations for intakes of total energy, foods and nutrients related to disease risk $^{7-12}$. A substantial body of literature indicates that parents and other caregivers can influence the food choices of young children through the types of food made available at home, interactions that take place during meals and eating behaviours they model ${ }^{13-17}$. However, questions remain regarding the degree of influence that parents have on their adolescents' dietary intake.

As youth enter adolescence, concerns with their appearance, growing independence, peer social norms and the media influence their food choices ${ }^{18,19}$. Although adolescents continue to consume the majority of meals and snacks at home, they also have considerably greater 
independence and autonomy when making food choices away from home ${ }^{20}$. In designing effective nutrition interventions for adolescents, it is important to establish whether home and parental influences on food choice are important factors to address. Despite the multiple influences on food choices during this time, research has found that adolescents perceive their home food environment and parental eating patterns as factors that influence their dietary intake $\mathrm{in}^{18,21,22}$. The availability of less healthful food choices at home is consistently reported as a key barrier to choosing fruit, vegetables and dairy foods in qualitative research ${ }^{19,21,22}$. While adolescents are willing to purchase snacks for themselves, they are less willing to purchase fruits or vegetables than sweet or salty convenience items ${ }^{21}$. To change their eating patterns, adolescents participating in these studies noted they need parents to encourage and model healthy eating $^{18,22}$. Research studies have also found that adolescents' reports of the home food environment and parental eating patterns are associated with their dietary intakes ${ }^{23-26}$; however, in studies where both adolescents and parents independently report their dietary intake, researchers have not always found associations ${ }^{8,27}$. In a study examining family influences on fat, sodium and calorie consumption, Patterson and colleagues found that intakes of parents and their young children (5th and 6th grade), but not their older children (mean age 13 years), were related ${ }^{8}$.

Less research has examined parent report of the home food environment and associations with adolescent dietary intakes. Parent report might be a more valid measure; parents may have a better sense for home availability of specific foods as they primarily control what foods are purchased for and served in the home. Clearly, parental reports of their own eating behaviours are also likely to be more accurate and could differ from adolescent report as adolescents will report what they perceive their parents eat. Thus, in examining the potential influence of home and family on adolescent dietary intake, there are advantages to obtaining parent report on the home availability of targeted foods and on parental dietary intake patterns.

In order to develop effective family-based intervention programmes, it is necessary to fully understand parental perceptions of the home environment and associations with dietary intakes of their adolescents. This study utilises a large, cross-sectional dataset with information from a diverse population of adolescents on their intakes of fruits, vegetables and dairy foods; information from parents on household food availability; and parent reports of their own intake. Adolescent intakes of fruits, vegetables and dairy foods were selected to examine the potential influence of home and parents because of the importance of these foods for health outcomes ${ }^{28,29}$; low consumption of fruits and vegetables places individuals at risk for cardiovascular disease and certain cancers, and low calcium consumption increases risk for osteoporosis ${ }^{30-32}$. Few adolescents are consuming the amounts recommended in the US Department of Agriculture (USDA) Food Guide Pyramid of at least two daily servings of fruits, at least three daily servings of vegetables and at least two daily servings of dairy foods ${ }^{28,29,33}$. The relationship between household availability of soft drinks and adolescent dairy intake was also explored, as research suggests that adolescents who consume more soft drinks have lower intakes of milk ${ }^{34,35}$. Research questions to be addressed in the current study include:

1. Is there an association between parent report of household fruit, vegetable, dairy foods and soft drink availability and adolescent intake of these foods?

2. Is there an association between dietary intakes of parents and their adolescents for fruits, vegetables and dairy foods?

\section{Methods}

\section{Study design}

Project EAT (Eating Among Teens) was a cross-sectional study of adolescents from public middle schools and high schools in the Minneapolis, St. Paul and Osseo school districts in Minnesota ${ }^{36,37}$. The study was based in a social cognitive framework, and the Project EAT survey was designed to assess socio-environmental, personal and behavioural factors that impact the nutritional health of adolescents. Student assessments included the Project EAT survey and the Youth Adolescent Food Frequency Questionnaire (YAQ), which measures usual dietary intake. Trained research staff administered the EAT survey to students during regular class periods during the 19981999 school year. A total of 4746 students participated in Project EAT (81.5\% of eligible students).

A subset of Project EAT participants were selected for parent assessment $(n=1182)$. To select the subset, participants were stratified by race/ethnicity and within each stratum, a predetermined proportion was randomly selected. This sampling design ensured the subset would be racially/ethnically heterogeneous. A modified version of the Project EAT survey was administered to parents via telephone by a trained interviewer, within one month after their adolescent completed surveys at school. For consistency, an effort was made to interview the adolescent's mother unless it was established that she did not reside in the same household. In this situation, the primary caregiver was interviewed. Typically, three to four calls were made to each home to reach the mother or primary caregiver; however, some households were called 20-25 times. Telephone interviews lasted 12 to $15 \mathrm{~min}$. Nine hundred and two parents participated $(76.3 \%$ of the selected subset). The final sample for the present study consists of 902 adolescents ( 424 boys and 478 girls) and 
their parents (810 females and 92 males; one parent per adolescent). Further details of the sample and data collection procedures are given elsewhere ${ }^{38,39}$.

Prior to use, student and parent versions of the Project EAT survey ${ }^{40}$ were pre-tested among samples (68 adolescents and 15 parents) from schools not participating in the study. An interdisciplinary team of experts in the field reviewed multiple iterations of the survey. Additional details about survey development are available elsewhere $^{39}$.

Study procedures were approved by the University of Minnesota Human Subjects' Committee and by the research boards of participating school districts. Passive and active consent procedures were followed in accordance with the participating school board procedures.

\section{Measures}

\section{Adolescent dietary intake}

Servings of fruits, vegetables and dairy foods consumed by adolescents were measured with the 149-item, semiquantitative Youth Adolescent Food Frequency Questionnaire ${ }^{41,42}$. Total fruit servings were summarised from reported consumption of 11 fruits and juices. Vegetable servings were summed from intakes of 16 different vegetables, mixed vegetables, tomato sauce and coleslaw. Intakes of French fries and potato salad were excluded from final calculations of total vegetable servings as these foods are less nutrient-dense than most vegetable choices and analyses with and without these foods yielded virtually identical results. Dairy servings were summed from reported intakes of milk, yoghurt, cheese, ice cream and mixed dishes such as macaroni and cheese. Details of the foods included within each food group on the questionnaire are described in the Appendix. The YAQ is one of the most comprehensive dietary assessment instruments that have been validated in adolescents ${ }^{41}$. Reliability and validity for this tool have been documented elsewhere $^{42,43}$.

\section{Parent dietary intake}

Parental dietary intake was assessed with measures modified from the 5-a-Day Power Plus Program parent survey $^{44}$. Intake of fruit was assessed with the question: 'Thinking back over the past week, how many servings of fruit did you usually eat on a typical day. . . zero; less than 1 serving; 1 serving; 2 servings; 3 servings; 4 servings; or 5 or more servings?' Similar questions were used to assess intake of vegetables and dairy foods. Serving sizes were defined for parents during the interviews as $1 / 2$ cup or 1 medium piece for fruit, $1 / 2$ cup cooked or 1 cup raw for vegetables, and 1 cup milk or yoghurt or $1 \mathrm{oz}$ cheese for dairy foods. Few parents reported consuming less than 1 serving or more than 4 servings of any food. Therefore, responses were categorised as less than 1 serving, 1 serving, 2 servings, 3 servings and 4 or more servings.

\section{Parent report of housebold food availability}

Measures used to assess household food availability were modified from items on the 5-a-Day Power Plus Program parent survey or developed for the survey following focus group research with adolescents ${ }^{18,44}$. Availability of fruits and vegetables was assessed by parent report in response to the question: 'How often would you say fruits and vegetables are available in your home... (1) always; (2) usually; (3) sometimes; or (4) never?' Similar questions were used to assess household availability of soft drinks, how often vegetables were served at dinner and how often milk was served at meals. As few parents reported fruits and vegetables were never available in their home $(n=1)$ or vegetables never served at dinner $(n=6)$, these responses were combined with 'sometimes' responses for analyses.

\section{Demographics}

The Project EAT student survey collected information on demographic characteristics including adolescent gender and current grade. Adolescents were classified as middleschool or high-school students. During the telephone survey, parents were asked to report demographic information including their gender, determinants of socio-economic status and race/ethnicity. The primary determinants of socio-economic status were parents' selfreported education level, family income and job status $^{38,45}$. Race/ethnicity was assessed with the question: 'Which of these best describes you... (1) White; (2) Black or African American; (3) Hispanic or Latino; (4) Asian or Asian American; (5) Native Hawaiian or other Pacific Islander; (6) American Indian or Native American?' Parents choosing to report a race/ethnicity not given as a response option or multiple response options $(n=7)$ were coded as 'mixed or other'. As few parents reported 'Native Hawaiian or other Pacific Islander' or 'American Indian or Native American', these parents $(n=55)$ were included with the 'mixed or other' parents.

\section{Statistical analyses}

Descriptive statistics were calculated for the independent variables, parent report of intake and availability. Continuous dependent variables (intakes by adolescents) were adjusted for positive skewness with square root transformations. Spearman correlations were examined between the transformed dietary intakes, household food availability and parental intakes.

General linear modelling was used to contrast the transformed dietary intakes of adolescents across different levels of household food availability and parental intakes (unadjusted models). Given prior research suggesting that intakes of fruits, vegetables and dairy foods are related to demographic characteristics, all models were re-calculated adjusting for school level (i.e. middle vs. high school), parent socio-economic status, parent gender and parent race/ethnicity in multivariate models ${ }^{46-48}$. Because estimated mean values derived from unadjusted and 
adjusted models were very similar, only adjusted models are presented here. Estimated mean intakes of adolescents, at each level of independent variables, calculated in general linear models were squared in order to transform them back to the original scale, and are therefore reported in Tables 3 and 4 as median intakes ${ }^{49}$. For all models, $t$ tests of trend were examined to assess the linearity of adolescent intake across different levels of household food availability and parental intakes. Interaction terms were added to general linear models to test for interaction between the two independent variables, and to examine whether relationships between each independent variable and adolescent intake varied by race/ethnicity or socioeconomic status.

To facilitate comparison with prior research, male and female parents were combined in the analysis ${ }^{14,15,50}$. All analyses were conducted with SAS statistical software, version 8.2 (SAS Institute, Cary, NC, USA).

\section{Results}

\section{Characteristics of the sample}

Among the 902 adolescent participants, 47\% were boys, $60 \%$ were in high school and 40\% were in middle school. Of the 902 adult respondents, 92\% were biological parents $(n=826), 3 \%$ stepparents $(n=26)$ and 5\% other guardians $(n=50)$. Hereafter all guardians are referred to as 'parents'. Parent respondents self-reported their race/ethnicity; approximately 43\% were white, $22 \%$ black, $18 \%$ Asian $(72 \%$ of the Asian parents reported that they were Hmong), 10\% Hispanic and 7\% other/mixed. The majority of parents were married (63\%) and working outside the home (82\%).

\section{Intakes of fruits, vegetables and dairy foods}

Many adolescents and parents were not meeting the USDA Food Guide Pyramid ${ }^{29}$ recommendations for fruits, vegetables and dairy intake (Table 1). Approximately half of boys and girls were not consuming the minimum number of daily recommended fruit servings (boys: $54.9 \%$, girls: $49.0 \%$ ) and a majority were not meeting recommendations for vegetable servings (boys: 88.5\%, girls: 83.8\%). Approximately one-third (boys: $27.0 \%$, girls: $36.2 \%$ ) of adolescents were not consuming the minimum number of recommended dairy food servings. Among parents, a little less than one-half were not consuming the minimum number of recommended fruit $(44.5 \%)$ or dairy food servings (46.9\%). The majority of parents were not consuming the minimum number of recommended vegetable servings (69.9\%).

\section{Housebold food availability}

Parental reports of household fruit, vegetable, dairy and soft drink availability are presented in Table 2. Most parents reported fruits and vegetables were at least usually available in their home (90.4\%). The majority of parents also reported that vegetables (87.0\%) and milk (66.6\%) were at least usually served with meals. Soft drinks were at least usually available in the majority of homes (56.9\%).

\section{Associations between bousebold food availability and adolescent intakes}

Spearman correlations ranged between 0.05 and 0.19 for household availability and adolescent intakes of fruit, vegetables and dairy foods. Associations were found between some parent reports of household food availability and adolescent intakes (Table 3). Intakes of fruits and vegetables were positively associated with household availability for girls $\left(t_{\text {trend }}=2.70, P<0.01\right.$ ), but not for boys. Median intakes indicate that 1.3 additional servings of fruits and/or vegetables were consumed by girls in homes where fruits and vegetables were always available versus sometimes/never available. No association was found between vegetable intake and the frequency of serving vegetables at dinner for boys or girls.

For dairy foods, the availability of milk appeared to matter more for boys and the availability of soft drinks to

Table 1 Adolescents' and parents' daily intakes of fruits, vegetables and dairy foods*

\begin{tabular}{lccccc}
\hline & \multicolumn{5}{c}{ Servings } \\
\cline { 2 - 6 } & $<1$ & 1 & 2 & 3 & $\geq 4$ \\
\hline Boys & & & & \\
$\quad$ Fruits & $25.4(99)$ & $29.5(115)$ & $15.9(62)$ & $10.5(41)$ & $18.7(73)$ \\
$\quad$ Vegetables & $45.9(180)$ & $29.8(117)$ & $12.8(50)$ & $5.4(21)$ & $6.1(24)$ \\
$\quad$ Dairy foods & $7.4(30)$ & $19.6(79)$ & $16.9(68)$ & $16.1(65)$ & $40.0(161)$ \\
Girls & & & & & \\
$\quad$ Fruits & $23.9(106)$ & $25.1(111)$ & $16.9(75)$ & $11.3(50)$ & $22.8(101)$ \\
$\quad$ Vegetables & $39.0(173)$ & $32.6(145)$ & $12.2(54)$ & $8.1(36)$ & $8.1(36)$ \\
$\quad$ Dairy foods & $11.4(52)$ & $24.8(113)$ & $19.9(91)$ & $16.7(76)$ & $27.2(124)$ \\
Parents & & & & & \\
$\quad$ Fruits & $14.7(132)$ & $29.8(268)$ & $28.6(257)$ & $14.7(132)$ & $12.2(109)$ \\
$\quad$ Vegetables & $8.4(76)$ & $33.9(306)$ & $27.6(249)$ & $12.0(108)$ & $18.1(163)$ \\
Dairy foods & $19.8(178)$ & $27.1(244)$ & $26.4(238)$ & $15.7(142)$ & $11.0(99)$ \\
\hline
\end{tabular}

Values are expressed as $\%(n)$.

${ }^{\star}$ Foods within each of the food groups are listed in the Appendix. 
Table 2 Parental report of household food availability

\begin{tabular}{lcccr}
\hline & Always & Usually & Sometimes & Never \\
\hline Fruits and vegetables at home & $65.7(592)$ & $24.7(223)$ & $9.5(86)$ & $0.1(1)$ \\
Vegetables served at dinner & $56.9(513)$ & $30.1(272)$ & $12.3(111)$ & $0.7(6)$ \\
Milk served at meals & $50.1(451)$ & $16.5(149)$ & $22.5(203)$ & $10.9(98)$ \\
Soft drinks at home & $40.6(365)$ & $16.3(147)$ & $36.7(331)$ & $6.4(58)$ \\
\hline
\end{tabular}

Values are expressed as $\%(n)$.

Table 3 Adjusted adolescent intakes (servings) of fruits, vegetables and dairy foods by availability

\begin{tabular}{|c|c|c|c|c|c|c|c|c|}
\hline & \multicolumn{4}{|c|}{ Boys } & \multicolumn{4}{|c|}{ Girls } \\
\hline & $n$ & Median† & $t_{\text {trend }}$ & $P$-value & $n$ & Median† & $t_{\text {trend }}$ & $P$-value \\
\hline \multicolumn{9}{|c|}{ Fruit/vegetable intake by household availability } \\
\hline Sometimes/never & 379 & 3.48 & 0.13 & 0.89 & 429 & 2.69 & 2.70 & $<0.01$ \\
\hline Usually & & 3.00 & & & & 3.44 & & \\
\hline Always & & 3.42 & & & & 3.99 & & \\
\hline \multicolumn{9}{|c|}{ Vegetable intake by vegetables served at dinner } \\
\hline Sometimes/never & 381 & 1.21 & 1.14 & 0.89 & 431 & 1.16 & 1.58 & 0.11 \\
\hline Usually & & 1.24 & & & & 1.34 & & \\
\hline Always & & 1.19 & & & & 1.47 & & \\
\hline \multicolumn{9}{|c|}{ Dairy intake by milk served at meals } \\
\hline Never & 391 & 2.04 & 3.65 & $<0.01$ & 442 & 2.51 & 1.35 & 0.18 \\
\hline Sometimes & & 3.24 & & & & 2.39 & & \\
\hline Usually & & 3.15 & & & & 2.53 & & \\
\hline Always & & 3.48 & & & & 2.89 & & \\
\hline \multicolumn{9}{|c|}{ Dairy intake by household availability of soft drinks } \\
\hline Never & 391 & 3.24 & 0.21 & 0.83 & 442 & 3.63 & 2.08 & 0.04 \\
\hline Sometimes & & 3.35 & & & & 2.56 & & \\
\hline Usually & & 2.64 & & & & 2.54 & & \\
\hline Always & & 3.38 & & & & 2.72 & & \\
\hline
\end{tabular}

*Adjusted for school level, parent gender, parent socio-economic status and parent race/ethnicity.

$\dagger$ Values on the original scale ranged from zero to $\geq 4$. Transformed estimated means were squared and approximate medians on the original scale. A higher median value indicates a greater number of servings.

be most important for girls. A significant linear trend was found suggesting that a greater number of daily servings was consumed by boys when milk was more frequently served at meals $\left(t_{\text {trend }}=3.65, P<0.01\right)$. Median intakes indicate that 1.4 additional servings were consumed by boys in homes where milk was always served at meals versus never. Although girls also reported drinking more milk when the beverage was always served at meals, this trend was not statistically significant. The pattern of dairy consumption among boys was not related to household availability of soft drinks, but a significant linear trend was observed for girls suggesting greater intakes of dairy foods when soft drinks are less available $\left(t_{\text {trend }}=2.08, P=0.04\right)$. Adjusted median intakes indicated that when girls always had soft drinks available at home they consumed 0.9 fewer servings of dairy foods than girls who never had soft drinks at home. Girls in homes where soft drinks were usually or sometimes available also consumed approximately 1 less serving of dairy foods per day than did adolescents who never had soft drinks at home.

\section{Associations between intakes of parents and their adolescents}

Spearman correlations ranged between 0.06 and 0.17 for parent and adolescent intakes of fruits, vegetables and dairy foods. Some associations were observed between intakes of parents and their adolescents (Table 4). Significant associations were found for girls' intakes of fruits $\left(t_{\text {trend }}=3.17, \quad P<0.01\right)$ and vegetables $\left(t_{\text {trend }}=3.72, P<0.01\right)$. Median intakes indicate that girls consumed 1.1 additional servings of fruits and 1.0 serving of vegetables when their parents consumed 4 or more servings versus less than 1 serving of these foods. Parent intakes were unrelated to intakes of fruits and vegetables among boys. A strong association was also found for dairy foods; the number of servings consumed by both boys $\left(t_{\text {trend }}=2.04, P=0.04\right)$ and girls ( $\left.t_{\text {trend }}=2.43, P=0.01\right)$ varied significantly with parental intakes. Median intakes indicate that boys consumed 0.9 additional servings of dairy foods and girls 0.6 additional servings when their parents consumed 4 or more dairy servings versus less than 1 serving a day. No consistent pattern of interactions was apparent between household availability and parent intake, or between these variables and race and socio-economic status.

\section{Discussion}

This study examined associations between parental report of household food availability and adolescent intakes of fruits, vegetables and dairy foods. Median intakes increased among adolescents as their parents reported 
Table 4 Adjusted ${ }^{\star}$ adolescent intakes (servings) of fruits, vegetables and dairy foods by parent intakes (servings)

\begin{tabular}{|c|c|c|c|c|c|c|c|c|}
\hline \multirow[b]{2}{*}{ Parent intakes } & \multicolumn{4}{|c|}{ Boys } & \multicolumn{4}{|c|}{ Girls } \\
\hline & $n$ & Median† & $t_{\text {trend }}$ & $P$-value & $n$ & Median† & $t_{\text {trend }}$ & $P$-value \\
\hline \multicolumn{9}{|l|}{ Fruit } \\
\hline$<1$ & 378 & 2.10 & 0.10 & 0.92 & 427 & 1.49 & 3.17 & $<0.01$ \\
\hline 1 & & 1.80 & & & & 2.25 & & \\
\hline 2 & & 2.12 & & & & 2.12 & & \\
\hline 3 & & 1.96 & & & & 2.34 & & \\
\hline$\geq 4$ & & 2.05 & & & & 2.62 & & \\
\hline \multicolumn{9}{|l|}{ Vegetables } \\
\hline$<1$ & 381 & 1.23 & 0.40 & 0.69 & 431 & 0.67 & 3.72 & $<0.01$ \\
\hline 1 & & 1.18 & & & & 1.47 & & \\
\hline 2 & & 1.14 & & & & 1.27 & & \\
\hline 3 & & 1.28 & & & & 1.42 & & \\
\hline$\geq 4$ & & 1.30 & & & & 1.71 & & \\
\hline \multicolumn{9}{|l|}{ Dairy foods } \\
\hline$<1$ & 392 & 2.87 & 2.04 & 0.04 & 441 & 2.50 & 2.43 & 0.01 \\
\hline 1 & & 3.27 & & & & 2.30 & & \\
\hline 2 & & 3.14 & & & & 2.82 & & \\
\hline 3 & & 3.43 & & & & 3.01 & & \\
\hline$\geq 4$ & & 3.73 & & & & 3.06 & & \\
\hline
\end{tabular}

${ }^{*}$ Adjusted for school level, parent gender, parent socio-economic status and parent race/ethnicity.

$\dagger$ Values on the original scale ranged from zero to $\geq 4$. Transformed estimated means were squared and approximate medians on the original scale. A higher median value indicates a greater number of servings.

these foods were more frequently available in the home. Significant associations were found for fruit and vegetable intake by home availability among girls and for dairy intake by serving milk at meals among male adolescents. Our findings for girls are in agreement with most previous research examining fruit and vegetable intake patterns among children and adolescents ${ }^{14,17,23}$. In a review of psychosocial correlates of dietary intake, Baranowski and colleagues noted that despite a limited amount of research in adolescents, important correlates for modifying fruit and vegetable intake likely include parental intakes and availability ${ }^{17}$. Several studies with elementary-school children have related home availability of fruits and vegetables to consumption ${ }^{14,15}$. One study that examined fruit and vegetable consumption among 13 third-grade students and their families found significant positive associations between availability and intakes for fruit or $100 \%$ juices, vegetables and combined servings of fruit and vegetables ${ }^{14}$. Similarly, qualitative and quantitative studies among adolescents have consistently reported that adolescents perceive the availability of fruits, vegetables and dairy foods and the absence of unhealthful alternatives to influence their intakes of these foods ${ }^{18,19,21-23}$. In the complete sample of 4746 adolescents who participated in Project EAT, a study which analysed adolescent report and not parent report of intake and availability to identify factors associated with fruit and vegetable intake, home availability was found to be the strongest correlate in structural equation models ${ }^{23}$.

As adolescents reported their own intake and availability data were reported separately by parents, the present study provides additional support for these previous findings that have related household food availability to fruit and vegetable consumption during adolescence. However, the finding for frequency of serving vegetables at dinner was not consistent with prior research suggesting meal-time availability is associated with intakes of fruit and vegetables ${ }^{14,51-53}$. We did not find associations between adolescent vegetable intake and parental report of serving vegetables at dinner. One possible explanation is a lack of variability in responses to this item; the majority of parents reported vegetables were always served at dinner. Alternatively, a difference might only be observable among adolescents who more frequently eat dinner at home. In addition, the results reported here extend prior research to dairy foods and soft drinks. Dairy servings were positively associated with serving milk at meals among boys and inversely associated with home availability of soft drinks among girls. The results are in agreement with qualitative research among adolescents where the availability of unhealthful food choices has been identified as a barrier to making healthy food choices ${ }^{18,22}$.

This study also examined whether parent intake is associated with adolescent intake for fruits, vegetables and dairy foods. The finding that parent intakes were associated with their daughters' intakes and their sons' intakes of dairy foods extends the results of previous studies mostly limited to young children. Of prior studies which have reported associations between parents' fruit, vegetable and/or dairy consumption and intakes of their children, only five studies were found that included adolescents $8,26,27,54-57$. Two studies found associations between dairy intakes of mothers and their adolescents ${ }^{56,57}$. Results of the present study suggest that parents may continue to play a role in determining their child's consumption of fruits and vegetables as well as dairy foods during adolescence. The gender difference observed 
might be related to the large proportion of parent respondents that were female.

Our findings are also supported by the research of Lau and colleagues among a sample of primarily Caucasian males during late adolescence and young adulthood ${ }^{27}$. Lau et al. found a correlation between intakes of parents and intakes of their children for combined servings of fresh fruit, candy, whole-grain breads or cereals, fresh vegetables, regular soft drinks and 'junk' food ${ }^{27}$. The results of our study extend the generalisability of these findings to early adolescence. Findings of the present study are particularly significant in light of the low intakes of fruit, vegetables and dairy foods reported by adolescents and their parents in this sample and in other recent surveys ${ }^{48,58}$.

This study was strengthened by having data from a large sample of parents and their adolescents. The sub-sample studied was racially/ethnically heterogeneous and demographically diverse. A comprehensive instrument was used to assess the diets of adolescents and trained interviewers were employed to assess the dietary patterns and behaviours of parents. The effect of response bias on associations between household food availability and adolescent intake was minimised by the use of dietary consumption data reported by adolescents and household food availability data reported separately by parents.

When drawing conclusions from the results of this study, certain limitations should be taken into consideration. Response rates to surveys of adolescents (81.5\%) and parents (76.3\%) were high. However, adolescents in the subset who reported lower socio-economic status and non-white race on the Project EAT survey were less likely to be part of the final sample due to parent non-response. Dietary intake and food availability data were collected from self-report, which may be influenced by social desirability bias ${ }^{59}$. In addition, the tool used to assess home availability in the current study differed from those used elsewhere ${ }^{14,15,60-63}$, and has not been validated. However, our findings were in agreement with prior research studies that have assessed home food availability by summing yes/no responses for past week availability of individual fruits and vegetables ${ }^{14}$. Parent intake was assessed with a brief, unvalidated measure and it cannot be assumed that this measure yielded comparable results to estimates obtained for their adolescent's intake from a food-frequency questionnaire ${ }^{64}$. This limitation may have led to an underestimate of the association between parent and adolescent intake. There are also potential limitations of using the YAQ in an ethnically and socio-economically diverse sample. Although the YAQ is one of the most widely tested and validated instruments for use with adolescents $^{41-43}$, one study has demonstrated lower validity among African American youth, who make up a substantial proportion of the present study sample ${ }^{65}$. Finally, as the design of this research is cross-sectional, causality cannot be inferred.
Future research will need to examine whether the importance of modelling is dependent on the frequency of dining together and eating behaviours directly observed by adolescents. Research also needs to address whether the observed associations extend to specific fruits, vegetables and dairy foods (e.g. low-fat milk, yellow/ green vegetables, etc.). In particular, more work is needed to understand the impact household soft drink availability may have on intakes of dairy foods and calcium during adolescence. The inclusion of more fathers in research of this nature is needed to better examine associations with adolescent intake. Finally, intervention studies are needed as the observed variation in adolescent intakes of fruits, vegetables and dairy foods with household food availability and parental intakes may be reciprocally determined.

\section{Applications}

Although many adolescents frequently eat away from home and have substantial independence in making food selections, our findings suggest the home food environment is associated with consumption patterns. Interventions designed to increase intakes of fruits, vegetables and dairy foods among adolescents should consider targeting parents to increase household availability of these foods.

Further, interventions targeting adolescents' dietary behaviours would likely be enhanced by including a parental component aimed at increasing parental consumption of fruit, vegetables and dairy foods.

\section{Acknowledgements}

This study was supported by grant MCJ-270834 (D.N.-S., principal investigator) from the Maternal and Child Health Bureau (Title V, Social Security Act), Health Resources and Service Administration, and the US Department of Health and Human Services.

\section{References}

1 US Department of Agriculture, Agricultural Research Service. Results from USDA's 1994-1996 Continuing Survey of Food Intakes by Individuals and 1994-1996 Diet and Health Knowledge Survey [online]. Available at http://www.barc. usda.gov/bhnrc/foodsurvey/home.htm. Accessed 24 March 2003.

2 Sandler R, Slemenda C, LaPorte R, Cauley JA, Schramm MM, Barresi ML, et al. Postmenopausal bone density and milk consumption in childhood and adolescence. American Journal of Clinical Nutrition 1985; 42: 270-4.

3 Maynard M, Gunnell D, Emmett P, Frankel S, Smith G. Fruit, vegetables, and antioxidants in childhood and risk of adult cancer: the Boyd Orr cohort. Journal of Epidemiology and Community Health 2003; 57: 218-25.

4 Dietz W. Childhood weight affects adult morbidity and mortality. Journal of Nutrition 1998; 128: 411S-4S.

5 Kemm J. Eating patterns in childhood and adult health. Nutrition and Health 1987; 4: 205-15. 
6 Nicklas T, Farris R, Smoak C. Dietary factors relate to cardiovascular risk factors in early life. Arteriosclerosis 1988 ; 8: $193-9$.

7 Feunekes G, Stafleu A, de Graaf C, van Staveren W. Family resemblance in fat intake in The Netherlands. European Journal of Clinical Nutrition 1997; 51: 793-9.

8 Patterson T, Rupp J, Sallis J, Atkins C, Nader P. Aggregation of dietary calories, fats, and sodium in Mexican-American and Anglo families. American Journal of Preventive Medicine 1988; 4(2): 75-82

9 Laskarzewski P, Morrison J, Khoury P, Kelly K, Glatfeller L, Larsen $\mathrm{R}$, et al. Parent-child nutrient intake interrelationships in school children ages 6 to 19: The Princeton School District Study. American Journal of Clinical Nutrition 1980; 33: $2350-5$

10 Perusse L, Tremblay A, Leblanc C, Cloninger CR, Reich T, Rice J, et al. Familial resemblance in energy intake: contribution of genetic and environmental factors. American Journal of Clinical Nutrition 1988; 47: 629-35.

11 Fisher J, Mitchell D, Smiciklas-Wright H, Birch L. Parenta influences on young girls' fruit and vegetable, micronutrient, and fat intakes. Journal of the American Dietetic Association 2002; 102(1): 58-64.

12 Fisher J, Mitchell D, Smiciklas-Wright H, Birch L. Maternal milk consumption predicts the tradeoff between milk and soft drinks in young girls' diets. Journal of Nutrition 2000; 131: $246-50$.

13 Nicklas T, Baranowski T, Baranowski J, Cullen K, Rittenberg L, Olvera N. Family and child-care provider influences on preschool children's fruit, juice, and vegetable consumption. Nutrition Reviews 2001; 59(7): 224-35.

14 Hearn M, Baranowski T, Baranowski J, Doyle C, Smith M, Lin L et al. Environmental influences on dietary behavior among children: availability and accessibility of fruits and vegetables enable consumption. Journal of Health Education 1998; 29(1): 26-32.

15 Kratt P, Reynolds K, Shewchuk R. The role of availability as a moderator of family fruit and vegetable consumption. Health Education \& Behavior 2000; 27(4): 471-82

16 Birch L. Development of food preferences. Annual Review of Nutrition 1999; 19: 41-62.

17 Baranowski T, Cullen K, Baranowski J. Psychosocial correlates of dietary intake: advancing dietary intervention. Annual Review of Nutrition 1999; 19: 17-40.

18 Neumark-Sztainer D, Story M, Perry C, Casey M. Factors influencing food choices of adolescents: findings from focus-group discussions with adolescents. Journal of the American Dietetic Association 1999; 99(8): 929-34, 937.

19 Auld G, Boushey C, Bock M, Bruhn C, Gabel K, Gustafson D, et al. Perspectives on intake of calcium-rich foods among Asian, Hispanic, and White preadolescent and adolescent females. Journal of Nutrition Education and Behavior 2002; 34: $242-51$

20 Nielsen S, Siega-Riz A, Popkin B. Trend in food locations and sources among adolescents and young adults. Preventive Medicine 2002; 35: 107-13.

21 Hill L, Casswell S, Maskill C, Jones S, Wyllie A. Fruit and vegetables as adolescent food choices in New Zealand. Health Promotion International 1998; 13: 55-65.

22 O'Dea J. Why do kids eat healthful food? Perceived benefits of and barriers to healthful eating and physical activity among children and adolescents. Journal of the American Dietetic Association 2003; 103(4): 497-500.

23 Neumark-Sztainer D, Wall M, Perry C, Story M. Correlates of fruit and vegetable intake among adolescents: finding from Project EAT. Preventive Medicine 2003; 37: 198-208.

24 Backman D, Haddad E, Lee J, Johnston P, Hodgkin G. Psychosocial predictors of healthful dietary behavior in adolescents. Journal of Nutrition Education and Behavior 2002; 34: 184-93.
25 Woodward D, Boon J, Cumming F, Ball P, Williams H, Hornsby H. Adolescents' reported usage of selected foods in relation to their perceptions and social norms for those foods. Appetite 1996; 27: 109-17.

26 Lee S, Reicks M. Environmental and behavioral factors are associated with the calcium intake of low-income adolescent girls. Journal of the American Dietetic Association 2003; 103(11): 1526-9.

27 Lau R, Quadrel M, Hartman K. Development and change of young adults' preventive health beliefs and behavior: influence from parents and peers. Journal of Health and Social Behavior 1990; 31: 240-59.

28 US Department of Health and Human Services (DHHS) Nutriton and Overweight. Healthy People 2010: Understanding and Improving Health. Washington, DC: DHHS, 2000.

29 US Department of Agriculture (USDA), Center for Nutrition Policy and Promotion. Food Guide Pyramid. Home and Garden Bulletin No. 252. Washington, DC: USDA, 1996.

30 Steinmetz K, Potter J. Vegetables, fruit, and cancer prevention: a review. Journal of the American Dietetic Association 1996; 96(10): 1027-39.

31 Bazzano L, He J, Ogden L, Loria CM, Vupputuri S, Myers L, et al. Fruit and vegetable intake and risk of cardiovascular disease in US adults: the first National Health and Nutrition Examination Survey Epidemiologic Follow-up Study. American Journal of Clinical Nutrition 2002; 76: 93-9.

32 Heaney R. The importance of calcium intake for lifelong skeletal health. Calcified Tissue International 2002; 70: $70-3$.

33 Grunbaum J, Kann L, Kinchen S, Williams B, Ross JG, Lowry $\mathrm{R}$, et al. Youth risk behavior surveillance - United States, 2001. Morbidity and Mortality Weekly Report 2002; 51(SS-4): $1-62$.

34 Harnack L, Stang J, Story M. Soft drink consumption among US children and adolescents: nutritional consequences. Journal of the American Dietetic Association 1999; 99: 436-41.

35 Guenther P. Beverages in the diets of American teenagers. Journal of the American Dietetic Association 1986; 86(4): 493-9.

36 Neumark-Sztainer D, Falkner N, Story M, Perry C, Hannan P, Mulert S. Weight-teasing among adolescents: correlations with weight status and disordered eating behaviors. International Journal of Obesity and Related Metabolic Disorders 2002; 26: 121-31.

37 Neumark-Sztainer D, Story M, Hannan P, Perry C, Irving L. Weight-related concerns and behaviors among overweight and nonoverweight adolescents: implications for preventing weight-related disorders. Archives Pediatrics \& Adolescent Medicine 2002; 156: 171-8.

38 McGuire M, Hannan P, Neumark-Sztainer D, Cossrow NF, Story M. Parental correlates of physical activity in a racially/ethnically diverse adolescent sample. Journal of Adolescent Health 2002; 30: 253-61.

39 Neumark-Sztainer D, Wall M, Story M, Perry C. Correlates of unhealthy weight control behaviors among adolescents: implications for prevention programs. Health Psychology 2003; 22: 88-98.

40 Neumark-Sztainer D, Croll J, Story M, Hannan P, French S, Perry C. Ethnic/racial differences in weight-related concerns and behaviors among adolescent girls and boys: findings from Project EAT. Journal of Psychosomatic Research 2002; 53: $963-74$.

41 Rockett H, Berkey C, Colditz G. Evaluation of dietary assessment instruments in adolescents. Current Opinion in Clinical Nutrition and Metabolic Care 2003; 6: 557-62.

42 Rockett H, Wolf A, Colditz G. Development and reproducibility of a food frequency questionnaire to assess diets of 
older children and adolescents. Journal of the American Dietetic Association 1995; 95: 336-40.

43 Rockett H, Breitenbach M, Frazier A, Witschi J, Wolf AM, Field AE, et al. Validation of a youth/adolescent food frequency questionnaire. Preventive Medicine 1997; 26: 808-16.

44 Perry C, Bishop D, Taylor G, Murray DM, Mays RW, Dudovitz BS, et al. Changing fruit and vegetable consumption among children: The 5-a-Day Power Plus Program in St. Paul, Minnesota. American Journal of Public Health 1998; 88(4): $603-9$.

45 Fulkerson J, McGuire M, Neumark-Sztainer D, Story M, French S, Perry C. Weight-related attitudes and behaviors of adolescent boys and girls who are encouraged to diet by their mothers. International Journal of Obesity and Related Metabolic Disorders 2002; 26: 1579-87.

46 Krebs-Smith S, Cook D, Subar A, Cleveland L, Friday J, Kahle L. Fruit and vegetable intakes of children and adolescents in the United States. Archives of Pediatrics \& Adolescent Medicine 1996; 150: 81-6.

47 Reynolds K, Baranowski T, Bishop D, Farris RP, Binkley D, Nicklas TA, et al. Patterns in child and adolescent consumption of fruit and vegetables: effects of gender and ethnicity across four sites. Journal of the American College of Nutrition 1999; 18(3): 248-54.

48 Neumark-Sztainer D, Story M, Hannan P, Croll J. Overweight status and eating patterns among adolescents: where do youths stand in comparison with the Healthy People 2010 objectives? American Journal of Public Health 2002; 92(5): $844-51$.

49 Hoaglin D, Mosteller F, eds. Understanding Robust and Exploratory Data Analysis. New York: John Wiley and Sons, Inc., 1983.

50 Marsh T, Cullen K, Baranowski T. Validation of a fruit, juice, and vegetable availability questionnaire. Journal of Nutrition Education and Behavior 2003; 35(2): 93-7.

51 Neumark-Sztainer D, Hannan P, Story M, Croll J, Perry C. Family meal patterns: associations with sociodemographic characteristics and improved dietary intake among adolescents. Journal of the American Dietetic Association 2003; 103(3): 317-22.

52 Gillman M, Rifas-Shiman S, Frazier A, Rockett HR, Camargo $\mathrm{CA} \mathrm{Jr}$, Field AE, et al. Family dinner and diet quality among older children and adolescents. Archives of Family Medicine 2000; 9: 235-40.

53 Videon T, Manning C. Influences on adolescent eating patterns: the importance of family meals. Journal of Adolescent Health 2003; 32: 365-73.
54 Gibson E, Wardle J, Watts C. Fruit and vegetable consumption, nutritional knowledge and beliefs in mothers and children. Appetite 1998; 31: 205-28.

55 Longbottom $\mathrm{P}$, Wrieden W, Pinet C. Is there a relationship between the food intakes of Scottish $51 / 2-8$ 1/2-year-olds and those of their mothers? Journal of Human Nutrition and Dietetics 2002; 15(4): 271-9.

56 Johnson R, Panely C, Wang M. Associations between the milk mothers drink and the milk consumed by their schoolaged children. Family Economics and Nutrition Review 2001; 13(1): 27-36.

57 Grove T, Douglass J, Heimbach J, DiRenzo D, Miller G. Evaluation of maternal consumption of dairy products and its influence upon daughters' diets. FASEB Journal 1999; 13: A549.

58 Rafiroiu A, Anderson E, Sargent R, Evans A. Dietary practices of South Carolina adolescents and their parents. American Journal of Health Behavior 2002; 26(3): 200-12.

59 Herbert J, Clemow L, Pbert L, Ockene I, Ockene J. Social desirability bias in dietary self-report may compromise the validity of dietary intake measures. International Journal of Epidemiology 1995; 24: 389-98.

60 Reynolds K, Hinton A, Shewchuk R, Hickey C. Social cognitive model of fruit and vegetable consumption in elementary school children. Journal of Nutrition Education and Behavior 1999; 31: 23-30.

61 Cullen K, Baranowski T, Owens E, Marsh T, Rittenbery L, Moor CD. Availability, accessibility, and preferences for fruit, $100 \%$ fruit juice, and vegetables influence children's dietary behavior. Health Education \& Behavior 2003; 30(5): 615-26.

62 Cullen K, Baranowski T, Rittenberry L, Cosart C, Hebert D, deMoor C. Child-reported family and peer influences on fruit, juice and vegetable consumption: reliability and validity of measures. Health Education Research 2001; 16(2): $187-200$.

63 Weber Cullen K, Baranowski T, Rittenberry L, Cosart C, Owens E, Hebert D, et al. Socioenvironmental influences on children's fruit, juice and vegetable consumption as reported by parents: reliability and validity of measures. Public Health Nutrition 2000; 3(3): 345-56.

64 Amanatidis S, Mackerras D, Simpson J. Comparison of two frequency questionnaires for quantifying fruit and vegetable intake. Public Health Nutrition 2001; 4(2): 233-9.

65 Field A, Peterson K, Gortmaker S, Cheung L, Rockett H, Fox MK, et al. Reproducibility and validity of a food frequency questionnaire among fourth to seventh grade inner-city school children: implications of age and day-to-day variation in dietary intake. Public Health Nutrition 1999; 2: 293-300.

\section{Appendix - Food items on the Youth Adolescent Food Frequency Questionnaire by food group}

Fruits

Raisins, grapes, bananas, melon, apples, pears, oranges, strawberries, peaches, plums, orange juice, apple juice

Vegetables

Tomatoes, tomato or spaghetti sauces, string beans, broccoli, beets, corn, peas, mixed vegetables, spinach, greens or kale, peppers, yams, zucchini or squash, carrots, lettuce, coleslaw

Dairy

Milk, instant breakfast, yoghurt, cheese, cheeseburger, pizza, macaroni \& cheese, grilled cheese sandwich, nachos with cheese, pudding, frozen yoghurt, ice cream, milkshake 